\title{
Determinação da gemelaridade: do questionário de Peeters aos micro-satélites aleatórios espalhados pelo DNA
}

\author{
José António Ribeiro Maia ${ }^{1}$ \\ Sónia Cristina de Tavares e Cruz Fernandes ${ }^{1}$ \\ António Amorim² \\ Cíntia Alves ${ }^{2}$ \\ Leonor Gusmão² \\ Luísa Pereira ${ }^{2}$
}

https://doi.org/10.5628/rpcd.07.02.147

\section{RESUMO}

Com a realização deste estudo pretendíamos testar a validade de um método indirecto para avaliação da gemelaridade em estudos na população portuguesa. Da pesquisa participaram 96 gémeos (45 grupos gemelares monozigóticos e dizigóticos), de ambos os sexos, dos 6 aos 12 anos de idade, e as respectivas mães biológicas, num total de 141 sujeitos. A determinação da zigotia foi efectuada com recurso a dois métodos: (1) Método indirecto, através da aplicação do questionário de Peeters et al. (1998) às mães dos gémeos; (2) Método directo, através da recolha de sangue (pequena picadela no dedo) a cada um dos membros dos grupos de gémeos e posterior análise do DNA em laboratório. A proporção global de gémeos correctamente classificados como monozigóticos e dizigóticos com recurso ao questionário foi de $97,8 \%$. O valor do teste do qui-quadrado é altamente significativo $\left(\chi^{2}=41.053, p<0.0001\right)$, reforçado pelo teste de McNemar $(p<0.0001)$. Face aos resultados obtidos, conclui-se que o questionário de Peeters et al. (1998) apresenta validade transcultural para avaliação da gemelaridade em estudos na população portuguesa.

Palavras-chave: gemelaridade, gémeos, questionário, DNA, validade

\author{
${ }^{1}$ Laboratório de Cineantropometria \\ Universidade do Porto \\ Portugal \\ 2 IPATIMUP \\ Universidade do Porto \\ Portugal
}

\begin{abstract}
Zygosity determination: From Peeters' questionnaire to DNA microsatelites

This study had the purpose of testing the validity of an indirect method to assess zygosity in twin studies in the Portuguese population. The sample included 96 twins (45 monozygotic and dizygotic twin groups), of both sexes, from 6 to 12 yrs old, and their biological mothers, summing 141 subjects. Two methods were used to determine zygosity: (1) Indirectly, through Peeters et al. (1998) questionnaire filled out by the mothers; (2) Directly, through blood sampling of each twin member, and their DNA was analysed in the laboratory. Proportion of correct classification of twins as monozygotic or dizygotic through Peeters et al. (1998) Questionnaire was 97,8\%. The Qui-Square test was highly significant $\left(\chi^{2}=41.053, p<0.0001\right)$, and it was reinforced by McNemar test $(\mathrm{p}<0.0001)$. The results allow us to conclude that Peeters et al. (1998) Questionnaire shows transcultural validity to assess zygosity in twin studies in the Portuguese Population.
\end{abstract}

Key-words: gemelarity, twins, questionnaire, DNA, validity 


\section{INTRODUÇÃO}

A existência de gémeos é um fenómeno que tem interessado não exclusivamente os investigadores de ciências biológicas e sociais, mas também a população em geral desde longa data(28). Este é, sem dúvida, um grupo populacional fascinante no domínio das mais variadas características do ser humano, uma espécie de "experiência da própria Natureza" que se prende ao esclarecimento da enorme variabilidade nas mais diversas características do ser humano.

Cada pessoa tem duas séries de cromossomas, uma transmitida pelo pai a outra pela mãe. Cada cromossoma pode ser imaginado como uma sequência de genes, cada um desempenhando uma função particular. Espalhados entre os genes existem marcadores que não lhe são conhecidas quaisquer funções biológicas mas cuja transmissão é idêntica à dos genes. A ordem dos genes (e marcadores) num cromossoma é fixa, pelo que cada gene é encontrado sempre na mesma posição, chamada locus. Cada pessoa tem dois genes em cada locus, um da série de cromossomas herdada do pai e o outro da mãe. Em cada locus os genes assumem diferentes formas, cada uma chamada de alelo. Dois genes que assumem a mesma forma são designados de idênticos pelo estado (do inglês identical-by-state - IBS). Dois genes podem ser IBS, por serem originários do mesmo descendente, e são réplicas do mesmo gene ascendente. Este tipo de partilha de genes é designado de identidade pela descendência (identity-by-descendent - IBD). Os genes podem também ser IBS não por causa de serem IBD mas devido a uma coincidência. Os gémeos monozigóticos (MZ) têm ambos os genes IBD em todos os loci do genoma. Em contraste, os gémeos dizigóticos (DZ) têm $25 \%$ de probabilidades de terem ambos os genes IBD, $50 \%$ de que um gene seja IBD e $25 \%$ de nenhum gene ser IBD em cada locus. Se um par de gémeos, num dado locus não for IBD em ambos os genes será, portanto, DZ.

A distinção de gémeos em $\mathrm{MZ}$ e $\mathrm{DZ}$ tem origens no século XIX, com Sir Francis Galton (1822-1902), mas foi apenas no século XX que surgiram os primeiros estudos $(24,18)$, com o intuito de averiguar uma base objectiva para o diagnóstico da zigotia, os quais deram origem ao método clássico de estudos com gémeos que ao longo do século assumiu uma enorme aplicabilidade(19). Até aos procedimentos mais actuais, com base no DNA houve certamente um caminho interessante onde alguns nomes deram passos marcantes na história da determinação da zigotia1. A identificação precisa da zigotia dos gémeos, i.e., saber se a gemelaridade é $\mathrm{MZ}$ ou $\mathrm{DZ}$, não tem sido tarefa fácil para os geneticistas interessados no fenómeno da gemelaridade, tão pouco para os obstetras no momento do parto gemelar(11), a não ser que as membranas fetais sejam monocoriónicas. Apesar do exame das membranas fetais ser considerado por Derom et al.(5) como o único método que permite ter a certeza da identificação de gémeos $\mathrm{MZ}$, Segal(27) estimou que mesmo os obstretas mais experientes classificam erradamente a zigotia em $6 \%$ dos casos e Elston et al.(7) referiram a necessidade de observação microscópica para distinguir a placentação monocorial (verificada nos gémeos MZ) de placentas dicoriónicas de dois embriões que se fundiram (gémeos DZ). A investigação no vasto território da Genética do comportamento (do inglês Behavioral Genetics) ou da Epidemiologia Genética aplicada às Ciências do Desporto com delineamentos gemelares necessita que se distingam claramente os gémeos $\mathrm{MZ}$ dos $\mathrm{DZ}$ (ver extensas aplicações deste tipo de pesquisa em Bouchard et al. (2). Por exemplo, a qualidade e generalização dos resultados de investigação "relativamente simples" de agregação familiar nos níveis e padrões de actividade física $(20,15,25)$, até matérias de maior repercussão, como transplante de órgãos, tratamentos farmacológicos ou transfusões sanguíneas (33, 12, 32) exigem a determinação precisa da gemelaridade dos grupos.

É pois da maior relevância a identificação precisa, fiável e válida da zigotia(33) respondendo, de modo inequívoco, à seguinte questão: estes gémeos são $\mathrm{MZ}$ ou DZ? Claro que se forem os dois de sexo oposto (cerca de 1/3 dos nascimentos gemelares), a resposta é óbvia - só podem ser dizigóticos ${ }^{2}$. Contudo, se forem do mesmo sexo, a resposta já não é tão óbvia.

Ao longo do tempo, os geneticistas foram desenvolvendo um conjunto variado de procedimentos de complexidade técnica e computacional diversa, que colectivamente podem ser agrupadas em dois tipos de métodos: directos e indirectos (ver por exemplo 28, 1, 23). Uma aventura interessante é a leitura da dissertação de doutoramento do geneticista belga Robert Vlietinck(33) ao dedicar-se, exclusivamente, ao lato e difícil assunto da determinação da gemelaridade, 
desenvolvendo técnicas simples cuja utilização o autor deseja generalizar.

Apesar de técnicas moleculares poderem estabelecer o diagnóstico com uma taxa de precisão de cerca de $100 \%$ e formas não invasivas de obtenção do DNA terem sido desenvolvidas(6), o custo destes procedimentos limita o seu uso em estudos epidemiológicos em larga escala(4). Portanto, não será de estranhar que o uso de questionários em matéria de determinação da zigotia tenha sido crescente nos últimos anos ${ }^{3}$.

A estratégia centrada na utilização dos questionários é bem simples - tornar acessível um procedimento válido e fiável, de baixíssimo custo, para estimar a zigotia do grupo. É evidente que o processo de validação concorrente do questionário tem sido objecto de sofisticação e refinamento por parte de procedimentos técnicos mais actuais e também do recurso a análises estatísticas mais poderosas(ver, por exemplo, 4, 37). O propósito deste nosso estudo radica precisamente nesta estratégia, pelo que pretendemos testar, uma vez mais, a qualidade do questionário de Peeters et al. (21) na determinação da zigotia. Este propósito é tanto mais válido quando não existe nenhum questionário, que seja do nosso conhecimento, de determinação da zigotia validado para a população portuguesa e quando se pretende que o seu uso seja "generalizado" por investigadores portugueses, nomeadamente das Ciências do Desporto, sempre que a sua amostra for constituída por pares de gémeos e enfrentar problemas sérios de financiamento para determinar a zigotia dos sujeitos com base no seu DNA.

\section{METODOLOGIA}

\section{Amostra}

A amostra do estudo foi recolhida fundamentalmente em dois Encontros de Gémeos realizados no Centro de Portugal: Cantanhede e Viseu, durante os quais foi feita uma reunião com os pais das crianças onde lhes foram explicados os propósitos e alcances da pesquisa e os procedimentos que seriam adoptados. Foi obtido consentimento expresso para participarem por parte dos pais em somente 52 casos. Porém, apenas foram validados para o nosso estudo, por questões processuais, 45 destes grupos gemelares assim distribuídos (ver quadro 1): 40 pares de gémeos, 4 grupos de trigémeos e 1 grupo de quadrigémeos, o que perfaz 96 gémeos dos 6 aos 12 anos de idade, 47 do sexo masculino e 49 do sexo feminino (uma distribuição praticamente equitativa quanto à variável género). Participaram também, através do preenchimento do questionário de Peeters, as respectivas mães (45).

Quadro 1. Distribuição da amostra por grupos gemelares e sexo

\begin{tabular}{lccc}
\hline grupos & sexo & $n$ & $\%$ \\
\hline Par gémeos (40; 88.9\%) & MM & 40 & 41.7 \\
& MF & 4 & 4.2 \\
& FF & 36 & 37.5 \\
\hline Trigémeos (4; 8.9\%) & MMM & 3 & 3.1 \\
& FFF & 9 & 9.3 \\
\hline Quadrigémeos (1; 2.2\%) & MMFF & 4 & 4.2 \\
\hline 45 & & 96 & 100 \\
\hline \multicolumn{4}{c}{ M-Masculino; F- Feminino } \\
\end{tabular}

\section{Instrumentos e Procedimentos}

Actualmente poderemos considerar dois tipos de métodos: directos e indirectos. Os métodos directos incluem: (1) exame das membranas materno-fetais, (2) marcadores genéticos clássicos, (3) DNA. Os indirectos são constituídos por uma plêiade de técnicas: (1) apreciação somatoscópica pericial da morfologia externa, (2) dermatóglifos, (3) questionários. O quadro 2 mostra como é possível efectuar o diagnóstico com graus crescentes de fiabilidade.

Quadro 2. Sumário dos procedimentos usados para determinação da zigotia apresentados por Borges-Osório e Robinson (1) e Elston et al. [7]. Sequência crescente em termos de Validade.

\section{Determinação da zigotia}

1. Regra diferencial de Weinberg

2. Comparação da similaridade

3. Questionários de similaridade

Auto-registo

Registo de outros

4. Dermatóglifos

5. Exame das membranas materno-fetais

6. Marcadores genéticos

Grupos sanguíneos

Sistema HLA

Proteínas séricas

Enxertos de pele

7. Análise do DNA: marcadores moleculares altamente polimórficos 
Destes métodos, só trataremos de forma brevíssima as técnicas que mais nos interessam - o exame de micro-satélites ou STRs (Short Tandem Repeats ${ }^{4}$ ) dispersos de forma aleatória no genoma e os questionários que incluem perguntas de grau de similaridade distinta cujas estimativas de heritabilidade, para as características em apreço, são muito altas.

\section{Determinação da zigotia com base em micro-satélites do DNA}

A análise do DNA dos membros de cada par implica obtenção de uma amostra muito reduzida de sangue. Trata-se, pois, de um procedimento "algo invasivo", para o qual foi obtido consentimento por parte dos pais, realizado por um elemento experiente. Também poderia ser feito através de saliva ou esfregaço bucal, mas o sangue foi o material preferido. A técnica de extracção e amplificação do DNA por cadeia de reacção da polimerase é bem conhecida e está suficientemente explicada em qualquer manual de genética médica (uma leitura interessante sobre o assunto em língua portuguesa é o livro de Regateiro(23). A extracção do DNA a partir das amostras de sangue de 96 indivíduos foi efectuada com um método baseado na utilização da resina Chelex (13). Em todas as amostras de DNA, a análise de 17 STRs autossómicos (CSF1PO, D2S1338, D3S1358, D5S818, D7S820, D8S1179, D13S317, D16S539, D18S51, D19S433, D21S11, FGA, PD, PE, TH01, TPO e VWA) e o locus da Amelogenina (determinação do sexo), foi efectuada por amplificação por PCR, utilizando os kits comerciais Powerplex 16 System (Promega Corporation) e Identifiler (AB Applied Biosystems), de acordo com as instruções dos fabricantes.

A genotipagem foi efectuada em aparelhos ABI 310 Genetic Analyzer (AB Applied Biosystems), de acordo com as instruções do fabricante, por determinação do tamanho dos fragmentos de DNA e comparação com escalas alélicas fornecidos com os kits comerciais.

Nos casos onde os indivíduos apresentavam perfis genéticos de STRs idênticos, foi efectuado o cálculo de probabilidade de monozigotia, que segue, no fundamental, a metodologia de Essen-Møller( ${ }^{(8)}$ e que se baseia nas frequências génicas, neste caso determinadas na população residente no Centro e Norte de Portugal. Dada a relevância da informação obtida, particularmente para os gémeos e seus pais, foi elaborado um relatório com os resultados que posteriormente lhes foi enviado.

\section{Questionário de Peeters et al. (1998)}

Esta técnica não invasiva, facilmente operacionalizável, de custo baixíssimo, permite obter informação preciosa acerca da zigotia dos pares de forma quase imediata. O questionário de Peeters et al.(21) foi desenvolvido na Bélgica pela equipa do Professor Robert Vlietinck (Departamento de Genética Humana da Universidade Católica de Lovaina). É constituído por um conjunto muito simples de questões (ver anexo) apreciado exclusivamente pela mãe. Está organizado do seguinte modo: um grupo de perguntas simples acerca da similaridade dos membros do par e índices de similaridade que contêm questões relativamente à parecença dos membros de cada par, tal como são apreciados pelos pais, irmãos, professores, amigos e estranhos. Esta informação está dispersa no questionário do seguinte modo: opinião da mãe (item 1); similaridade global e confusão gemelar (itens 2 a 7 ) e similaridade específica (itens 8 e 9$)$.

Entre outros, é possível calcular um índice designado por índice simples de similaridade que foi o utilizado nesta pesquisa. O seu cálculo é efectuado do seguinte modo: adiciona-se 1 ponto a cada resposta que indique similaridade entre os gémeos e subtraise 1 ponto a cada resposta que sugira dissemelhança. Gémeos DZ duvidosos são cotados com - 1/2 e gémeos $\mathrm{MZ}$ duvidosos com $+1 / 2$. Se a soma simples das cotações das respostas for igual ou superior a zero, os sujeitos são considerados gémeos MZ. Caso contrário, são referidos como gémeos DZ.

A recolha dos dados com base nos questionários foi feita durante os Encontros. Estes foram sempre cotados pelo mesmo investigador (J.A.R.M.), muito experiente e bem familiarizado com o instrumento e procedimentos. Conforme é descrito na literatura, uma amostra menor foi re-cotada para se obter uma estimativa da fiabilidade dos resultados. A consistência das cotações foi elevada, confirmando a qualidade da avaliação efectuada. 


\section{Procedimentos estatísticos}

Inicialmente, e após o procedimento descrito para estimar a fiabilidade dos resultados, foi calculada a percentagem de acordos de classificação (questionário - DNA) com base nas percentagens de classificações correctas nos gémeos MZ e DZ. O Kappa de Cohen foi utilizado para a correcção desta estatística, assumindo que classificações certas podem ter ocorrido de modo "casual". Com o intuito de testar formalmente a qualidade da informação das mães recorremos ao teste de qui-quadrado e ao teste de McNemar, esperando uma forte associação entre as duas classificações.

O software estatístico utilizado foi o SPSS 13.0.

\section{RESULTADOS}

Os principais resultados encontram-se sumariados no Quadro 3.

Quadro 3. Tabela de dupla entrada relativa às frequências e percentagens de classificação gemelar obtidas com o Questionário e os micro-satélites do DNA dos sujeitos

\begin{tabular}{|c|c|c|c|}
\hline \multirow[t]{2}{*}{ Classificação } & & \multicolumn{2}{|c|}{ Informação do DNA } \\
\hline & & $\mathrm{DZ}$ & $\mathrm{MZ}$ \\
\hline \multirow[t]{5}{*}{ Informação do Questionário } & $\mathrm{DZ}$ & $18(94.7 \%)$ & $1(5.3 \%)$ \\
\hline & & $40 \%$ & $2.2 \%$ \\
\hline & $M Z$ & $0(0 \%)$ & $26(100 \%)$ \\
\hline & & $0 \%$ & $57.8 \%$ \\
\hline & & 18 & 27 \\
\hline
\end{tabular}

DZ - Dizigótico; MZ - Monozigótico. Total: 45 grupos de gémeos

O teste da zigotia com base nos micro-satélites de DNA permitiu classificar correctamente os 96 indivíduos da amostra: 35 (40\%) são gémeos DZ e os restantes 61 (60\%) são gémeos MZ. Dos 19 grupos de gémeos $\mathrm{DZ}$ que foram identificados como tal através da cotação do questionário, 18 (94.7\% dos gémeos DZ) foram confirmados com a informação proveniente do DNA. Apenas 1 par (i.e., $2.2 \%$ do total da amostra) foi erradamente classificado. A sua zigotia correcta é MZ. Nos gémeos $\mathrm{MZ}$ a percentagem de classificação correcta é de $100 \%$, i.e. 26 em 26 grupos de gémeos foram correctamente classificados através do questionário.
A proporção global de acordo é calculada somando os resultados correctamente classificados como $\mathrm{MZ}$ e DZ, obtendo-se deste modo o seguinte valor: $(18+26) / 45=0.977$, i.e. $97.8 \%$, um valor bastante elevado. Decorrente deste procedimento chegamos também ao valor da percentagem de erros de classificação de $2.2 \%$.

Os resultados significativos obtidos no teste Kappa de Cohen $(0.954 \pm 0.045, \mathrm{p}<0.000)$, mostram claramente a relevância e a qualidade da informação obtida através do questionário, já que este é um teste que permite aferir a concordância ou semelhança entre os procedimentos por nós utilizados, cujo valor máximo é 1 e valores acima de 0.75 significam uma excelente concordância entre as variáveis. O valor do teste do qui-quadrado é altamente significativo $\left(\chi_{(1)}^{2}=41.053, p<0.0001\right)$. Estes resultados implicam uma forte associação entre a classificação reportada pelas mães e os resultados do DNA, resultados que são reforçados pelo teste de McNemar $(p<0.0001)$. Este último, também designado nas ciências sociais de teste de mudança de opinião, compara em termos percentuais as respostas dicotomizadas de duas variáveis, no nosso caso a classificação com base nos questionários e a classificação proveniente da análise do DNA, em amostras emparelhadas, o que igualmente se verifica no estudo por nós efectuado uma vez que os gémeos classificados nos dois procedimentos foram os mesmos. O valor de prova obtido com o teste foi menor que $1 / 1000$, o que nos leva à conclusão de que a classificação dos gémeos através dos questionários não alterou significativamente a classificação obtida pelo outro procedimento utilizado. $\mathrm{O}$ valor encontrado salienta o facto de não haver qualquer diferença significativa entre os resultados das frequências de respostas de zigotia do questionário e o exame do DNA.

\section{DISCUSSÃO}

Destes resultados emergem os seguintes comentários:

- A elevada associação entre a classificação das mães e os resultados do DNA vem confirmar a qualidade da informação do progenitor e a "capacidade" do questionário em determinar de modo simples e altamente económico a zigotia dos pares de gémeos. - A validade dos questionários já havia sido ante- 
riormente confirmada $(21,4,31,26)$ e é suportada em toda a magnitude no caso dos gémeos MZ. Já nos $\mathrm{DZ}$, os valores mostram erros de classificação de cerca de $2.2 \%$. Resultados equivalentes aos nossos foram já reportados por outros autores, cuja percentagem de erros varia entre 0 e $7 \%$. Convém referir que as amostras de estudos referenciados na introdução, bem como a que foi utilizada no questionário de Peeters, se situam entre os 100 e os 150 pares de gémeos, manifestamente superiores às do presente estudo. Daqui que apresentemos a sugestão de ser efectuado um estudo com uma amostra maior, tal como é sugerido por Mange e Mange ${ }^{(17)}$ para comprovar, de modo cruzado, a fiabilidade dos resultados, ainda que estejamos convictos que os resultados na população portuguesa não serão muito distintos dos que foram por nós obtidos.

- O facto do grau de concordância entre a classificação através do questionário e do teste de DNA, relativamente aos gémeos $\mathrm{MZ}$, ter sido de $100 \%$ poderia eventualmente suscitar a curiosidade dos motivos conducentes a uma total concordância entre a informação proveniente dos dois métodos, já que vários autores (e.g. 24, 14, 9, 32, 22) estudaram e assinalaram as diferenças comportamentais, físicas, genéticas e epigenéticas nos gémeos $\mathrm{MZ}$, tendo inclusive conduzido à subdivisão destes em três tipos $(23,33,11,1)$. Clarificando melhor: os gémeos $\mathrm{MZ}$ provêm de um ovo que foi fecundado e que em determinado momento se divide em duas "cópias genéticas". O momento da divisão dos blastómeros ${ }^{5}$ traduz-se depois em diferenças, mesmo físicas (cujo exemplo, talvez o mais perceptível seja o dos gémeos siameses), dissimilitudes que frequentemente se acentuam ao longo da vida dos gémeos. As dissemelhanças dos gémeos, a que as mães tendem a ser mais sensíveis, e o esforço que fazem por tratar os seus filhos individualmente foram os motivos apontados pela equipa de investigação do Professor Vlietinck, no estudo de Peeters et al.(21), para o facto de ter verificado valores inferiores de concordância nos gémeos $\mathrm{MZ}$ do que nos gémeos DZ. Porém, os pais usualmente distinguem os gémeos MZ(32). De facto, "apesar de os gémeos $M Z$ parecerem indistinguíveis aos estranhos, nenhuns gémeos são tão idênticos que as suas mães não os consigam distinguir sem errar" (10, p.105), o que torna este questionário ainda mais válido.
- O valor de erros de classificação é altamente aceitável no domínio da investigação no âmbito das Ciências do Desporto. Talvez não o fosse em outros campos da investigação, como o demonstra claramente a experiência vivenciada pelos gémeos St. Clair(32). Desde bastante cedo pensaram ser gémeos DZ por apresentarem alguns traços discordantes, ainda que fossem muito similares na aparência. John St. Clair, após uma intoxicação com cogumelos venenosos, recebeu um transplante renal do seu irmão David. Durante 15 anos John foi submetido a tratamentos de imunossupressão, com bastantes complicações daí derivadas. Perante a possibilidade de interromper o tratamento, caso se verificasse monozigotia, efectuaram vários testes de DNA que confirmaram serem MZ. Nove meses depois de ter interrompido os tratamentos com imunossupressores John mantinha uma função renal normal, confirmando 15 anos de tratamentos escusados. Não obstante os erros passíveis de serem encontrados na determinação da zigotia através deste procedimento, não há que retirar qualquer valor à informação do questionário. Bem pelo contrário!

- Ainda que o valor do erro seja baixo e seja o esperado, cremos que este tem uma explicação no contexto deste estudo. Nenhuma das mães tinha a certeza absoluta da zigotia dos seus filhos. Não tinha informação proveniente do exame do DNA, ou de qualquer exame de anatomia patológica à placenta. Curiosamente, a mãe que afirmava que os seus filhos eram gémeos DZ (pelo menos foram estes os resultados emergentes das suas respostas ao questionário), sempre tratou os seus filhos de modo diferente. Isto é, ainda que sejam $\mathrm{MZ}$, procurou sempre um espaço de intervenção de forte dissemelhança entre os membros do par. A diferença foi o seu toque no processo de relacionamento e educação. $\mathrm{E}$ de algum modo sugeriu que todos os tratassem desse modo. Este é um tipo de comportamento frequente entre as mães que vêem os seus filhos de forma diferente, ainda que possam ser "iguais" do ponto de vista genético. Este fenómeno é bem reportado na literatura, de que o texto "gémeos, trigémeos e mais"(3) dá conta.

— É evidente que a determinação da gemelaridade é um fenómeno que encerra em si mesmo um espaço para a incerteza, ainda que a probabilidade de se 
errar com os resultados dos micro-satélites seja baixíssima $(24,4,35,36)$. Contudo, não é impossível. Mais "fácil" é o erro de classificação com base nos questionários. Enquanto que na primeira técnica a probabilidade é muito próxima de $0 \%$, na segunda é cerca de 1 a $5 \%$. Há pois aqui que estabelecer um compromisso entre precisão do resultado e o respectivo custo, que é sempre elevado quando se recorre ao exame do DNA e se lida com centenas de sujeitos. - Da aplicação do questionário fica-nos porém a seguinte sugestão: ainda que o valor do inventário de Peeters seja inquestionável, há que recolher das mães um rigor ainda maior no modo como respondem às questões. Verificámos que porventura são confundidos os aspectos de natureza comportamental com as características físicas dos filhos para permitir tornar mais perceptíveis as "igualdades ou desigualdades” perante elas próprias e terceiros. Com esta ênfase serão claramente distinguidas impressões subjectivas e atitudes relativamente ao comportamento dos gémeos das suas opiniões quanto às características físicas dos mesmos.

Em conclusão, o questionário de Peeters de determinação da zigotia é um instrumento válido e fiável para ser utilizado em pesquisa gemelar no espaço lusófono.

\section{AGRADECIMENTOS}

1) este estudo foi financiado por uma bolsa de investigação da Fundação para a Ciência e Tecnologia (POCI/DES/62499/2004); (2) ao revisor anónimo, cujas sugestões ajudaram a melhorar alguns aspectos do texto.

\section{NOTAS}

${ }^{1}$ A este propósito ver os percursos históricos sumariamente descritos por Vlietinck (33), Borges-Osório e Robinson (1) e Spector et al. (30).

2 Gringras e Chen (10) descreveram vários efeitos intra-uterinos e mecanismos genéticos que podem resultar em diferenças fenotípicas, genéticas e epigenéticas nos gémeos $\mathrm{MZ}$, inclusive no que respeita ao sexo.

3 Um percurso histórico pode ser efectuado nos textos de Sarna et al. (26), de Chen et al. (4) e de von Wurmb-Shwark et al. (34).

${ }^{4}$ Short Tandem Repeat Polimorphism, também designado por micro-satélites, são repetições de 3 ou 4 nucleótidos com extensão reduzida e bem localizada ao longo do genoma humano que permite mapear informação importante, neste caso, a presença dos mesmos micro-satélites nos mesmos lugares dos cromossomas dos gémeos MZ.

${ }^{5}$ É hoje aceite pela comunidade científica distintos momentos de separação dos blastómeros: se a separação for precoce, até ao $3^{\circ}$ dia, os dois embriões implantam-se de forma autónoma no endométrio, originando uma placentação bicorial biamniótica; se a divisão do embrião ocorre entre o $3^{\circ}$ e o $7^{\circ}$ dia (a mais frequente), formam-se assim dois gémeos $\mathrm{MZ}$ com uma placenta comum, mas cada um com o seu saco amniótico - monocorial biamniótica; se a divisão ocorre após a primeira semana (com uma frequência $<1 \%$ dos gémeos $\mathrm{MZ}$ ), os gémeos partilham uma mesma placenta e um saco amniótico comuns. No caso dos gémeos siameses (que chegam a partilhar órgãos) a divisão do embrião ocorre para além das duas semanas de desenvolvimento.

\section{CORRESPONDÊNCIA}

José António Ribeiro Maia

Laboratório de Cineantropometria

Faculdade de Desporto, Universidade do Porto

Rua Dr. Plácido Costa, 91

4200-450 Porto 


\section{REFERÊNCIAS BIBLIOGRÁFICAS}

1. Borges-Osório, M.; Robinson, W. (2002). Genética humana. Artmed. Porto Alegre.

2. Bouchard, C.; Malina, R.; Pérusse, L. (1997). Genetics of fitness and physical performance. Human Kinetics. Champaign.

3. Bryan, E. (1995). Twins, triplets \& more. Their nature, development \& care. Penguin Books. London.

4. Chen, W.; Chang, H.; Wu, M.; Lin, C.; Cheng, C.; Chiu, YN.; Soong, W-T. (1999). Diagnosis of zygosity by questionnaire and polymarker polymerase chain reaction in young twins. Behaviour Genetics 29 (2):115-123.

5. Derom, R.; Vlietick, R.; Derom, C.; Keith, L.; Van Den Derghe, H. (1991). Zygosity testing at birth: A plea to the obstetrician. J Perinat Med 19: 234-240.

6. Dugoff, L.; Litman, E.; Hobbins, J.; Leslie, K (1995). A non-invasive approach in prenatal determination of fetal Rhesus D Status by DNA amplification. J Soc Gynecol Invest 2 (2): 184.

7. Elston, R.; Olson, J.; Palmer, L. (2002). Biostatistical genetics and genetic epidemiology. John Wiley \& Sons, Ltd. Londres

8. Essen-Møller, E. (1939)* . Die beweiskraft der ahnlichkeit im vaterschftsnachweiss. Theoretische brundlagen. Mitt. Anthrop. Ges. Wien. 68:9-53.

9. Gingras, P. (1999). Identical differences. The Lancet 353: 562.

10. Gingras, P.; Chen, W. (2001). Mechanisms for differences in monozygous twins. Early Human Development 64:105117.

11. Hall, J. G. (2003). Twinning. The Lancet 362:735-743.

12. Keith, L.; Machin, G. (1997). Zygosity testing: current status and evolving issues. J Reprod Med 11: 699-707.

13. Lareu MV, Phillips CP, Carracedo A, Lincoln AJ, Syndercombe Court D, Thomson JA (1994) Investigation of the STR locus HUMTH01 using PCR and two electrophoresis formats: UK and Galician Caucasian population surveys and usefulness in paternity investigations. Forensic Sci Int 66: 41-52.

14. Loos, R.; Beunen, G.; Fagard, R.; Derom, C.; Vlietinck, R.; Phillips, D. (2001). Twin Studies and Estimates of Heritability. The Lancet. 357, 1445.

15. Maia, J. A. R.; Thomis, M.; Beunen, G. (2002). Genetic factors in physical activity. A twin study. American Journal of Preventive Medicine 23(2S):87-91.

16. Maia, J.; Lopes, V. (2003). Estudo do crescimento somático, aptidão física, actividade física e capacidade de coordenação corporal de crianças do $1^{\circ}$ CEB da Região Autónoma dos Açores. DREFD, DRCT e FCDEF-UP (eds). Porto.

17. Mange, E.; Mange, A. (1999). Basic Human Genetics. Sinauer Associates, Inc. Publishers, $2^{\text {nd }}$ ed. Massachusetts.

18. Merriman, C. $(1924)^{*}$. The intellectual resemblance of twins. Psychological monografs 33: 1-58.

19. Neale, M.; Cardon, L. (1989). Methodology for genetic studies of twins and families. Kluwer Academic Press. Dordrecht.

20. Oliveira, M.; Maia, J. (2002). Avaliação multimodal da actividade física. Um estudo exploratório em gémeos monozigóticos e dizigóticos. Porto. FCDEF-UP.
21. Peeters, H.; Van Gestel, S.; Vlietinck, R.; Derom, C.; Derom, R. (1998). Validation of a telephone zygosity questionnaire in twins of known zygosity. Behavioral Genetics 28:159-163.

22. Philips, D. (1993). Twin studies in medical research: can they tell us whether diseases are genetically determined? The Lancet 341: 1008-1009.

23. Regateiro, F. J. (2003). Manual de Genética Médica. Imprensa da Universidade. Coimbra.

24. Ricci, U.; Lapi, E.; Gaarduci, S.; Andreucci, E.; Bacci, C.; Toschi, B.; Brenner, C.; Uzielli, M. (2004). Twin zygosity studies with the formula from DNA - View's Kinship Module after molecular analysis by polymorphic markers. International Congress Series 1261: 452-453.

25. Sapage, I. L. L.; Maia, J. A. R. (2005). Factores Genéticos e Ambientais nos Níveis e Padrões de Actividade Física. Omniserviços: Lisboa (em preparação).

26. Sarna, S.; Kaprio, J.; Sistonen, P.; Koskenvuo, M. (1978). Diagnosis of twin zygosity by mailed questionnaire. Human Heredity 28:241-254.

27. Seagal, N. (1984). Zygosity diagnosis: laboratory and investigator's judgement. Acta Gen Med Gemellol 33: 515520.

28. Seagal, N. L. (1999). Entwined Lives. Dutton Books. New York.

29. Siemens, H. (1924). Zwiligspathologie: Ihre Bedeutung; ihre Methodik, ihre bisherigen Ergebnisse. Springer Verlag. Berlin.

30. Spector, T.; Snider, H.; MacGregor, A. (2000). Advances in twin and sib-pair analysis. Kniphorst London.

31. Spitz, E.; Moutier, R.; Reed, T.; Busnel, M.; Marchaland, C.; Poubertoux, P.; Carlier, M. (1996). Comparatives diagnoses of twin Zygosity by SSLP variant analysis. Behav Genet 26: 55-63.

32. St. Clair, D. M.; St. Clair, J. B.; Swainson, C. P.; Bamforth, F.; Machin, G. A. (1998). Twin zygosity testing for medical purposes. American Journal of Medical Genetics 77:412-414.

33. Vlietinck, R. F. (1986). Determination of the zygosity of twins. Dissertação de doutoramento. Departamento de Biologia Humana e Centro de genética Humana. Universidade Católica de Lovaina. Lovaina.

34. Von Wurmb-Schwark, N.; Schwark, T.; Christiansen, L.; Lorenz, D.; Oehmichen, M. (2004). The use of different multiplex PCRs for twin zygosity determination and its application in forensic trace analysis. Legal Medicine 6:125130.

35. Ward, K.; McInnes, A. (1995). Twin Zygosity using short tandem repeat DNA markers. J Soc Gynecol Invest 2 (2): 184

36. Zhang, Y.; Lawrence, S.; Ryder, O.; Zhang, Y.; Isaza, R. (2000). Identification of Monozygotic Twin Chimpanzees by Satellite Analysis. Am Journal of Primatololy 52: 101-106.

37. Zhao, J. H.; Sham, P. C. (1998). A method for calculating probability convolution using "ternary" numbers with application in the determination of twin zygosity. Computational Statistics \& Data Analysis 28:225-232. 


\section{fodefip}

\section{Duestionário de}

Gemelaridade

\begin{tabular}{|c|c|c|}
\hline \multicolumn{2}{|c|}{ Homo fini ar minol_ } & \multirow[t]{2}{*}{ 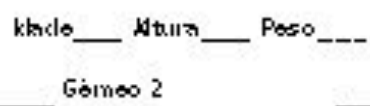 } \\
\hline Hoines & Exneo 1 & \\
\hline & Dentroo 3 & Gotues 4 \\
\hline
\end{tabular}

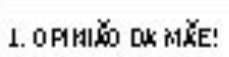

Fusa chio os solis yineor sio:

IDËHIIOOS (monor igoticos)?

FRKTERHOS [d rigotices]?

Toin a coltera cutu os solus yeineces sio:

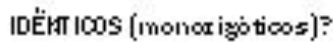

FRKTERHOS (d rigoticos)?

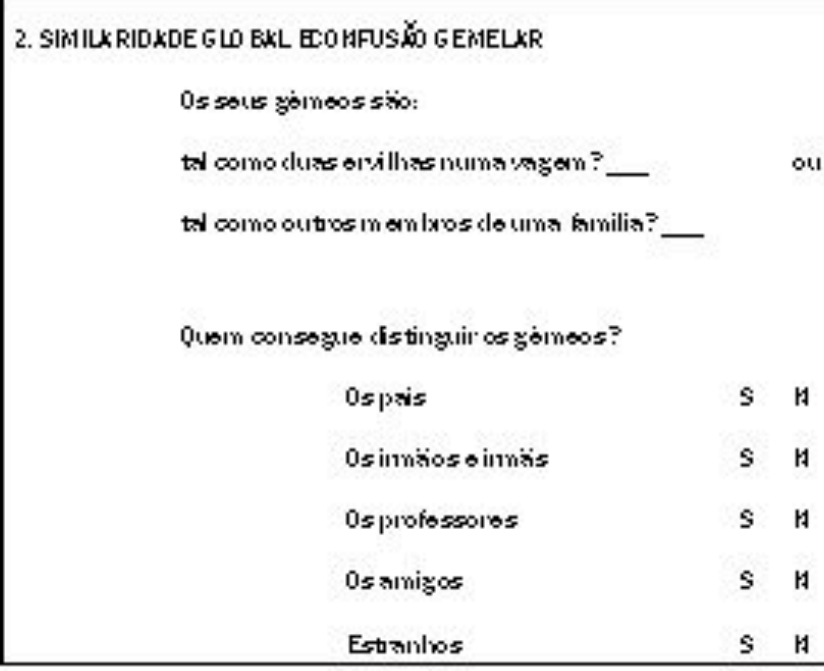

3. SIRIILFFIOKDE ESPECIACX

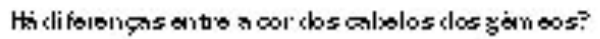

$S H$

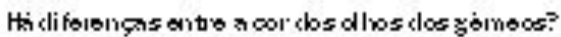

s $\mathrm{H}$

0bน 